The aim of this study is to evaluate the prevalence of gastrointestinal symptoms in caustic ingestion, the severity of lesions and the role of early conducted endoscopy in prediction of outcome. In a cross-sectional study all children hospitalized for caustic ingestion during two years, aged 12 years and younger were evaluated for clinical history, endoscopic findings, method of treatment and observed complications. Out of 51 children, 8 consumed acidic and 43 alkaline materials. The mean age of the children was $35.9+/-18$ months. Thirty four $(66.7 \%)$ patients were male and 17 (33.3\%) were female. In endoscopic survey, $38 \%$ had grade 1 and $62 \%$ had a burning intensity of grade 2 or higher. During the follow-up, esophageal structure developed in 5 cases and Gastric Outlet Obstruction (GOO) in 1 case. Two of 5 patients with stricture were treated by endoscopic dilatation and 3 of them underwent colon transposition surgery. Gastrectomy was done for the patient with GOO. Esophageal structure as a complication had a more incidence in acid ingestion. Gastric Otlet Obstruction (GOO) occurred in a case of acid ingestion. One of the patients died. Positive statistical relation between early endoscopic findings and complications found in control endoscopy suggest that early endoscopy probably is safe and provides important prognostic information. The role of prevention as a comprehensive strategy promoted by medical councils and the mass media is imperative.

\section{IMPACT OF A WORKING GROUP ON GASTROINTESTINAL DECONTAMINATION OF PEDIATRIC EMERGENCY IN SPAIN}

doi:10.1136/archdischild-2012-302724.0374

'R Velasco, ${ }^{2} \mathrm{Y}$ Acedo, ${ }^{2} \mathrm{~L}$ Del Arco, ${ }^{2} \mathrm{~N}$ Salmon, ${ }^{3} \mathrm{M}$ Palacios, Working Group of Poisonings of the Spanish Society of Pediatrics Emergencies. 'Pediatric Emergencies, Hospital Rio Hortega, Valladolid; 'Pediatrics, Hospital de Cruces, Barakaldo; ${ }^{3}$ Pediatrics, Complejo Universitario de Navarra, Pamplona, Spain

Introduction In a study conducted in 2001-02 including 17 pediatric emergency departments (PED) in Spain high variability was detected in management of acute pediatric intoxications and, more specifically in the gastrointestinal decontamination. Since that time, the Working Group of Intoxications (WGI) of the Spanish Pediatric Emergencies Society (SEUP) Poison designed and spread in different ways recommendations based on international guidelines based on scientific evidence about the management of these patients.

The objective of this study is to analyze the impact of the measures designed by the WGI in the management of acute intoxications in PED.

Patients and Methods Comparative study cohort. We analyze the management and, specifically, gastrointestinal decontamination in three time periods in the PED included in the WGI:

- Group A: 2001-02, 17 PED, 2157 episodes

- Group B: 2008-09, 37 PED, 612 episodes

- Group C: 2009-11: 42 PED, 400 episodes

Results Of the 3169 episodes recorded, 1031 (32'5\%)underwent for a gastrointestinal decontamination procedure (Group A: 34'1\%, Group B: 27.8\%, Group C: 31.5\%)

Of the patients who underwent gastrointestinal decontamination, technique used in each group are described in the following table.

Abstract 374 Table 1 Decontamination technique used in each group

\begin{tabular}{|c|c|c|c|c|c|c|}
\hline TECHNIQUE & $\begin{array}{l}\text { 2001-2002 } \\
\text { N (\%) }\end{array}$ & $\begin{array}{l}\text { 2001-2008 } \\
\text { N (\%) }\end{array}$ & 2009 N (\%) & ) $2010 \mathrm{~N}(\%)$ & 2011 N (\%) & $p$ \\
\hline $\begin{array}{l}\text { Activated } \\
\text { charcoal }\end{array}$ & $697(94,8)$ & $159(93,5)$ & $50(98)$ & $39(95,1)$ & 32 (96) & n.s. \\
\hline Gastric lavage & $214(29,1)$ & $48(28,2)$ & $16(31,4)$ & $12(29,3)$ & $5(14,7)$ & 0,08 \\
\hline Ipecac syrup & $168(22,8)$ & $3(1,7)$ & $0(0)$ & $0(0)$ & $0(0)$ & 0,0004 \\
\hline
\end{tabular}

Conclusions Recommendations developed and spread by a Working Group have approached the management of acute pediatric poisonings in Spain to international guidelines based on scientific evidence.

\section{PAEDIATRIC ABDOMINAL PAIN: A CALL FOR A BAYESIAN APPROACH TO DECISION MAKING}

doi:10.1136/archdischild-2012-302724.0375

${ }^{1,2} \mathrm{C}$ Beardsley, ${ }^{3} \mathrm{~A}$ Dillon, ${ }^{3} \mathrm{M}$ Chiu, ${ }^{4} \mathrm{R}$ Shaw, ${ }^{1,5} \mathrm{D}$ Croaker. ${ }^{1}$ Department of Surgery, The Canberra Hospital; ${ }^{2}$ Australian National University, Canberra, ACT; ${ }^{3}$ Nepean Hospital Sydney; ${ }^{4}$ Department of Surgery, Westmead Hospital, Sydney, NSW; ${ }^{5}$ ANU Medical School, Canberra, ACT, Australia

Background/aim of study Paediatric abdominal pain is a common. Efficient investigation and triage remains a challenge with stubborn rates of negative appendicectomy.

This study analysed the characteristics of paediatric presentations with abdominal pain.

Methods Retrospective review of presentations to casualty with abdominal pain in calendar years 2005-2006. Data was collected on age, sex, time of presentation, investigations and outcomes.

Main results 1.1007 patients presented with abdominal pain with a female preponderance. A peak in incidence about the age of 6-7 in both sexes was noted. The incidence in both sexes then stabilised till a pubertal rise in female incidence.

There is a seasonal variation with approx $25 \%$ more pain presentations in winter. No such seasonal effect was seen for appendicitis.

Overall abdominal pain is more likely to present after midday, while appendicitis presents throughout the day.

81 of 1007 patients had appendicectomies, 61 with appendicitis.

Adolescent females were much more likely to have normal appendixes removed, with $\mathrm{p}<0.001$.

2. Mean WCC was 15.1 for those with true appendicitis, compared to 11.4 for those with normal appendices: WCC sensitivity $87 \%$ and specificity $90 \%$.

In those who had ultrasound, the appendiceal visualisation rate was $57 \%$.

Conclusion Paediatric abdominal pain presentations vary in incidence depending on sex, age, season and time of day. Conditions requiring operation are relatively uncommon, and the patient's background, history and a priori likelihood of disease should be considered before ordering investigations or operation.

\section{EVALUATION OF KNOWLEDGE LEVEL ON CHILDHOOD ASTHMA AMONGST TEACHERS IN ISTANBUL}

doi:10.1136/archdischild-2012-302724.0376

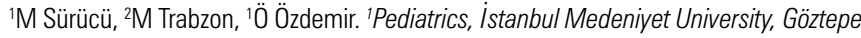
Research and Training Hospital, Kadiköy; ${ }^{2}$ Pediatrics, Okmeydani Research and Training Hospital, Okmeydani, Turkey

Aim A survey including the questions about the general information about childhood asthma, symptoms, triggers, emergency medical care in attack was applied to the teachers, and their education level was determined.

Patients/methods This study was done with the participation of randomly selected 826 teachers from 22 different $(20$ primary+middle and 2 high) schools between November to December 2011 in Istanbul. The teachers were questioned with a survey consisting of questions about the general information on asthma, symptoms, triggers, emergency care in the asthma attack, and therapy. Likert scale was used for the evaluation of answers (Disagree, Partly Disagree, Not Sure, Partly Agree and Agree).

Results The knowledge grades of general information on asthma were calculated as one of the highest, while the grades for triggers were found to be the lowest. According to the sex, the average grade 
level for female teachers about asthma was fairly higher than male ones. According to the education level, there was not a remarkable difference. According to the school types, public school teachers were somewhat lower than private school teachers. Asthma experience caused a meaningful increase in teachers' asthma knowledge level. According to the career duration between the teachers, the experienced teachers had more information about the triggers, whereas less experienced teachers were evaluated as well-informed about emergency medical care during the attack.

Conclusions The teachers having the knowledge about asthma reduce familial anxiety and school abstinence rate. This survey helps prepare a guideline for the next education programs and seminars amongst teachers.

\section{PREVALENCE OF HYPOSPADIAS IN DENMARK: A REGISTRY BASED POPULATION STUDY FROM 1986-2009}

doi:10.1136/archdischild-2012-302724.0377

${ }^{1} \mathrm{~KB}$ Nissen, ${ }^{2} \mathrm{~A}$ Udesen, ${ }^{3} \mathrm{E}$ Garne. ${ }^{1}$ Pediatrics, Hans Christian Andersen Childrens Hospital; '2Department of Plastic Surgery, Odense University Hospital, Odense; ${ }^{3}$ Department of Pediatrics, Division of Neonatology, Kolding, Denmark

Background Over the last decades the prevalence of hypospadia has been reported with increasing trends, but with widespread variation across countries.

The aim of this study was to determine the prevalence and trend of hypospadia over 23 years in a Danish population.

Design Population-based study of all infants born in the period 1986-2009 in Funen County, diagnosed with hypospadias and reported to the EUROCAT registry of congenital anomalies.

Cases were included only if surgery for hypospadias was performed or planned.

Results 201 cases of hypospadias were registered in 1986-2009 with an overall prevalence of 15.2 pr 10000 births. (95\% CI: 12.2 to 17.9). The prevalence of hypospadias increased from 4.1 in 1986 to 15.1 in 2009 with a peak prevalence in 2002 at 25.5 per 10000 births. The increase in prevalence was significant comparing the years $1986-1999$ to $2000-2009$ ( $p<0.001)$.

From 2000-2009 it was possible to specify the degree-of-severity of hypospadia. Infants with hypospadia as an isolated congenital anomaly were more likely to have a mild form of hypospadia (93\%) while cases with associated congenital anomalies had a lower proportion of mild hypospadias (58\%) $(\mathrm{p}<0,001)$.

Conclusion The prevalence of hypospadias has increased in a Danish county from 1986-2009 although from 2002 the rate seems to be levelling off. The aetiology of isolated hypospadias is multifactorial (paternal, maternal, endocrine and environmental factors). It is mandatory to have a comparable surveillance system in place to assess rates properly between countries in order to monitor changes in potential risk factors.

\section{GROWING UP HEALTHY IN GHANA II: SOCIOECONOMIC AND SPATIAL PREDICTORS}

doi:10.1136/archdischild-2012-302724.0378

B Reime, A Hahn, B Kreuels, W Loag, 0 Maiga, J May. Infectious Disease Epidemiology, Bernhard-Nocht-Institute for Tropical Medicine, Hamburg, Germany

Background and Aims Especially in resource poor settings measures for health promotion should be guided by evidence to channel expenditures according to populations' health priorities. Our aim was to identify predictors for infants' health amenable for short or midterm change to guide health policy decision making in Ghana. Methods This part of the Intermittent Preventive Treatment in Infants Trial used socioeconomic, behavioral and knowledge-related data that were collected on recruitment with interviews in the local language. Spatial data on the infants' residence area were measured by handheld global positioning system (GPS) receiver. We tested the association between these factors and health in bivariate and multivariable analyses adjusted for each other and for genetic and clinical factors.

Results In bivariate analyses, maternal age, financial status, TV, radio, refrigerator and kitchen in the house, malaria knowledge, effective protection against mosquitos and the villages' distance to the next hospital were related to health but birth order and water source were not. In multivariate analyses, infants from well-off families were twice as likely to grow up healthy $(\mathrm{OR}=2.03,95 \%$ $\mathrm{CI}=1.32-3.54)$ than infants from poor families. Type of mosquito protection and distance to hospital also were related to health.

Conclusions Independently of the child's genetic traits, effective protection against mosquitos and access to hospital may be related to better health outcomes in this area in Ghana. Further studies should explore how access to health services can be improved in remote settings. In the meantime, investment in effective mosquito protection may support growing up healthy in Ghana.

\section{HEALTH DISPARITIES IN WELL CHILD VISIT IN A COMPREHENSIVE PEDIATRIC CARE CENTER IN UNITED STATES: DOES INSURANCE MATTER?}

doi:10.1136/archdischild-2012-302724.0379

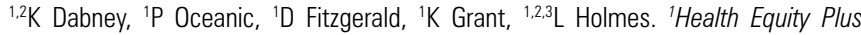
Inclusion; ${ }^{2}$ Orthopedic Department, Nemours/A.I. Dupont Children Hospital, Wilmington; ${ }^{3}$ Biological Sciences, University of Delaware, Newark, DE, USA

Background and Aims The Center for Disease Control and Prevention (CDC) provides guidelines on age-appropriate well child visist. We aimed in this study to examine the health disparities in well child prevalence.

Methods We examined data on children born between 2007 and 2009 in 2010/2011. Using the primary level of service (LOS) procedure codes: 99381, 99382, 99391, and 99392 (evaluation and management codes), we obtained 69,447 visit records (11,374 patients) The health disparities by race and insurance status were examined using Chi squared statistic and multivariable logistic regression.

Results A significant racial/ethnic disparities was observed: Caucasians (68.1\%) relative to African Americans/Blacks (46.1\%), Asians (66.3\%), Hawaian/PI (53.4\%), and some other race $(52.4 \%)$ were more likely to meet the recommended schedule, $\chi^{2}(7)=2,800$, $p<0.0001$. Similarly, higher compliance was associated with commercially insured patients $(73.4 \%)$, relative to Medicaid $(45 \%)$ or uninsured/Nemours subsidized (38.3\%), $\chi^{2}(2)=4,700, p<0.0001$. Compared with Caucasians, AA/Blacks were 60\% (Prevalence Odds ratio $[\mathrm{POR}]=0.40,95 \% \mathrm{CI}, 0.39-0.42)$, while Asians were $8 \%(\mathrm{POR}=$ $0.92 .95 \% \mathrm{CI}, 0.82-1.12)$ less likely to comply with the schedule. After controlling for insurance status, racial disparities was lowered, and AA/blacks were $42 \%$ less likely to comply compared with Caucasians, adjusted $\mathrm{POR}=0.58,99 \% \mathrm{CI}, 0.55-0.61$; and uninsured $/$ Nemours subsidized were $77 \%$ less likely to adhere to schedule relative to the commercially insured patients, adjusted POR, 0.23 , 99\%CI, 0.21-0.26

Conclusions Racial disparities exist in "well infant visit", and was not completely removed after adjustment for insurance staus which is known to influence access and care utilization.

\section{COMPARING THE EFFICACY OF TOPICALSUCRALFATE VERSUS TOPICAL ZINC OXIDE IN DIAPER DERMATITIS, A RANDOMIZED DOUBLE BLIND STUDY}

doi:10.1136/archdischild-2012-302724.0380

N Sajjadian, M Kadivar. Pediatric, Tehran Medical University, Tehran, Iran

Diaper dermatitis is one of the most common skin disorder during infancy. Different modality of treatment is suggested. Sucralfate 